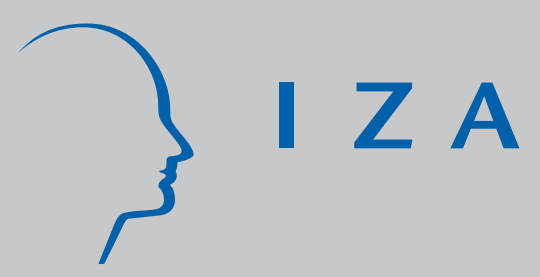

IZADP No. 3016

How Do Different Entitlements to Unemployment Benefits Affect the Transitions from Unemployment into Employment?

J ohn T. Addison

Pedro Portugal

August 2007 


\title{
How Do Different Entitlements to Unemployment Benefits Affect the Transitions from Unemployment into Employment?
}

\author{
John T. Addison \\ Queen's University Belfast, University of South Carolina, \\ Universidade de Coimbra/GEMF and IZA \\ Pedro Portugal \\ Banco de Portugal, Universidade Nova de Lisboa \\ and $I Z A$
}

Discussion Paper No. 3016

August 2007

IZA

P.O. Box 7240

53072 Bonn

Germany

Phone: +49-228-3894-0

Fax: +49-228-3894-180

E-mail: iza@iza.org

\begin{abstract}
Any opinions expressed here are those of the author(s) and not those of the institute. Research disseminated by IZA may include views on policy, but the institute itself takes no institutional policy positions.
\end{abstract}

The Institute for the Study of Labor (IZA) in Bonn is a local and virtual international research center and a place of communication between science, politics and business. IZA is an independent nonprofit company supported by Deutsche Post World Net. The center is associated with the University of Bonn and offers a stimulating research environment through its research networks, research support, and visitors and doctoral programs. IZA engages in (i) original and internationally competitive research in all fields of labor economics, (ii) development of policy concepts, and (iii) dissemination of research results and concepts to the interested public.

IZA Discussion Papers often represent preliminary work and are circulated to encourage discussion. Citation of such a paper should account for its provisional character. A revised version may be available directly from the author. 
IZA Discussion Paper No. 3016

August 2007

\begin{abstract}
How Do Different Entitlements to Unemployment Benefits Affect the Transitions from Unemployment into Employment?*

In Portugal duration of benefits is exclusively age determined while replacement rates are to all intents and purposes uniform. We exploit differences in potential maximum duration of benefits for nearly matched pairs of individuals who differ in age by one year and in potential maximum duration of benefits by three months. In specifications that take account of unobserved individual heterogeneity, while controlling for pure age effects on escape rates, we find that lower maximum benefit duration is associated with substantially higher quarterly rates of job finding in the range 53 to 106 percent.
\end{abstract}

JEL Classification: J64, J65

Keywords: $\quad$ unemployment benefits, unemployment duration, job search

Corresponding author:

Pedro Portugal

Banco de Portugal

Av. Almirante Reis 71

1150-165 Lisboa

Portugal

E-mail: pportugal@bportugal.pt

* The authors also gratefully acknowledge the partial financial support from Fundação para a Ciência e a Tecnologia. The usual disclaimer applies. 


\section{Motivation}

In this paper we investigate the disincentive effects of the Portuguese unemployment insurance system. Since replacement rates are near uniform we shall investigate the effects of benefit receipt and potential duration of unemployment insurance (UI) benefits. There are a number of papers charting the effects of benefit duration on joblessness that complement the replacement rate literature and generally report much stronger disincentive effects. ${ }^{1}$

Theory suggests that putting a limit on benefit duration will tend to accelerate job search and that benefit exhaustion will produce spike in escape rates Mortensen, 1977). The early empirical literature confirmed both predictions, namely, the reduction in escape rates/increase jobless duration with extended benefits (Katz and Meyer, 1990; Meyer, 1990) and the sharp increase in escape rates at benefit expiration (Katz and Meyer, 1990; Carling, Edin, Harkman, and Holmlund. 1996).

Such studies exploit changes in UI rules over time. However, an enduring concern has been endogenous policy bias, as will arise when more generous UI rules are introduced in anticipation of a deteriorating labor market. More recent studies therefore have either sought to identify legal changes in benefit duration that occur independently of labor market conditions (Card and Levine, 2000; Lalive and Zweimüller, 2004) or to exploit changes in the law that affect several categories of (treated) unemployed workers differently (with no change in benefits for another group of controls) for a reasonably long panel of data (Lalive, van Ours, Zweimüller, 2006; van Ours and Vodopivec, 2006). The results are again consistent with (job search) theory and are economically and statistically significant particularly for benefit duration where stronger disincentive effects are observed.

Here we deploy a methodology close to a regression discontinuity analysis to identify the impact of unemployment benefits on transition rates from unemployment into employment. We rely for traction on the fact that maximum duration

\footnotetext{
${ }^{1}$ On the cross-section replacement rate literature, see Atkinson and Micklewright, 1991; and, for more recent studies seeking to identify disincentive effects from regime changes, see inter al. Carling, Holmlund, and Vejsiu, 2001; Rød and Zhang, 2003.
} 
of benefits in Portugal is exclusively a function of age. Maximum potential benefit duration basically increases by 3 months at five-year age intervals. Focusing on paired sets of individuals on either side of each age-entitlement divide - who differ by just one year of age - we offer a treatment effect analysis of the impact of three-month increases in the maximum duration of benefits on transitions into employment. Our approach relies on a difference-in-differences framework for evaluating disincentive effects. That is, we will obtain estimates of the difference in transition rates among younger and slightly older individuals (the first difference) for unemployment recipients and non-recipients (the second difference).

To anticipate our findings, we first report strong evidence of disincentive effects using a discrete duration (complementary log-log) model. These effects persist after controlling for unobserved individual heterogeneity using a finite mixture distribution approach (viz. a two-mass point hazard model). We further report that our results on heterogeneity are consistent with a more parsimonious splitpopulation model in which a sizeable proportion of the unemployed is never allowed to exit joblessness. At all times, we control for the independent effects of age on escape rates, which are found to be monotonic and well determined.

\section{Data}

Our data are taken from the nationally representative Portuguese Quarterly Employment Surveys for the period 1992(2) to 1997(4). The choice of starting and ending date is dictated by changes in the methodology of the employment survey, including new sampling procedures and redefinition of the key unemployment variable, respectively. The survey has a quasi-longitudinal capacity: we have information on the length of the current unemployment spell (in months), and with one-sixth of the sample rotating out of the survey each quarter we can track transitions from unemployment into employment for up to five quarters.

Each survey contains information on the unemployment benefit status of the unemployed worker. It does not contain information on replacement rates. However, the UI replacement rate is in general a constant proportion (65 percent) of 
the previous wage. ${ }^{2}$ For this reason, our focus will be upon the role of potential benefit duration. Under Portuguese law, duration of benefits is purely age determined. The maximum duration of benefits is 10 months for those aged less than 25 years and 12 months for those aged between 25 and 29 years. It then rises in 3-month intervals for each incremental 5 years of age up to a maximun of 30 months at 55 years of age. We note parenthetically that duration entitlements did not change over the sample period.

We exploit this purely age-determined system of benefit entitlements in the present paper to determine the effects of benefit duration on escape rates from unemployment into employment by focusing on those age-adjacent - and hence roughly matched individuals - whose benefits differ by three months (actually 2 months in the case of those aged 24 to 25 years). Our sample thus comprises only those pairs of individuals aged 24 to 25 years, 29 to 30 years, 34 to 35 years, 39 to 40 years, 44 to 45 years, 49 to 50 years, and 54 to 55 years. The variable YOUNG will simply identify younger individuals in each age pair - irrespective of whether or not they draw benefits - the omitted category being those aged one year more. In other words, YOUNG takes the value of one whenever individuals are aged 24, 29, $34,39,44,49$, and 54 years. It will further be interacted with a receipt of benefits dummy to evaluate the disincentive effects of UI. Moreover, given well-known age effects on escape rates, we will also use six age dummies to determine the pure effect of age on escape rates/jobless duration. Here individuals aged 24 to 25 years will now constitute the omitted category, meaning that the first age dummy will be one for individuals aged 29 or 30 years, while the second age dummy will identify individuals aged 34 and 35, and so on. To estimate the discrete duration model we rely on episode-splitting along the lines proposed by Jenkins (1995). This approach implies that each spell of unemployment is transformed into a monthly series of binary indicators, identifying censored and exit times.

Finally, reflecting well-documented differences between the sexes in labor sup-

\footnotetext{
${ }^{2}$ Nevertheless, the 65 percent rule cannot yield less than the minimum wage for low-wage earners or more than three times the minimum wage for high-wage earners. Unfortunately, the dataset does not contain information on the previous wage of unemployed workers that would allow us to calculate replacement rates for these groups.
} 
ply, we restricted the sample to males. We also required that the individual be unemployed at the time of the survey, be aged between 16 and 64 years, and be resident in mainland Portugal.

\section{Model specification}

\subsection{The complementary log-log model}

In our exercise, duration is measured in months. Conventional continuous time duration models are clearly at odds with our data. We thus consider a simple discrete time duration model: the complementary log-log (cloglog) model. Let time be divided into $k$ intervals $\left[\tau_{0}, \tau_{1}\right),\left[\tau_{1}, \tau_{2}\right) \ldots\left[\tau_{k-1}, \infty\right)$. The researcher observes discrete time $T \in\{1, \ldots, k\}$, where $T=t$ denotes an exit within the interval $\left[\tau_{t-1}, \tau_{t}\right)$. The hazard function, which gives the conditional (on $t$ ) probability of exit, is given by

$$
h(t)=P(T=t \mid T \geq t), \quad \mathrm{t}=1,2, \ldots \mathrm{k}-1
$$

and the survivor function, which gives the probability of staying in the same state up until $t$ is defined as

$$
S(t)=P(T>t)=\prod_{j=1}^{t}[1-h(j)] .
$$

A useful extension of the proportional hazards model to discrete time starts from

$$
S\left(t \mid x_{i}\right)=S_{0}(t)^{\exp \left(x_{i}^{\prime} \beta\right)},
$$

where $S\left(t \mid x_{i}\right)$ gives the probability that individual $i$ with covariates $x_{i}$ will survive up to time $t$, and $S_{0}(t)$ denotes the baseline survivor function (that is, where the covariates equal zero). Given the relationship between the hazard and the survivor functions with discrete time, one can write

$$
1-h\left(t \mid x_{i}\right)=\left[1-h_{0}(t)\right]^{\exp \left(x_{i}^{\prime} \beta\right)},
$$

which leads the cloglog hazard function

$$
h\left(t \mid x_{i}\right)=1-\left[1-h_{0}(t)\right]^{\exp \left(x_{i}^{\prime} \beta\right)} .
$$


The baseline hazard function may then be parameterized using different functional forms (piecewise-constant, polynomial, logarithmic, etc.). The regression coefficients may be interpreted as in standard proportional hazards models. The model can be estimated straightforwardly transforming the duration data into binary outcomes, a procedure known as episode splitting. Fitting a generalized linear model with binomial error and complementary log-log link, leads to the following contribution of observation $i$ to the likelihhod function

$$
L_{i}=\left[\frac{h\left(t \mid x_{i}\right)}{1-h\left(t \mid x_{i}\right)}\right]^{c_{i}} \prod_{j=1}^{t}\left[1-h\left(j \mid x_{i}\right)\right],
$$

where $c_{i}$ identifies a complete spell of unemployment.

\subsection{The binomial-mixture duration model}

We generalize our model to accommodate the presence of unobserved individual heterogeneity. Unobserved individual heterogeneity may stem from omitted (or unobserved) covariates and/or measurement errors in duration. Here we will consider a simple model where we assume that two groups of individuals, in unknown proportions, are present in the data. The difference among the two groups stands from distinct intercepts. The group with the larger intercept (the hares) will leave unemployment at a faster rate than the group with the smaller intercept (the turtles). Formalizing this reasoning, we assume that the hazard function for a fraction $\pi$ of individuals is defined as

$$
h_{1}\left(t \mid x_{i}\right)=1-\left[1-h_{0}(t)\right]^{\exp \left(\beta_{0}+\beta_{1} x_{1 i}+\ldots+\beta_{k} x_{k i}\right)},
$$

while that of the remaining fraction of $1-\pi$ can be written

$$
h_{2}\left(t \mid x_{i}\right)=1-\left[1-h_{0}(t)\right]^{\exp \left(\beta_{0}+\delta+\beta_{1} x_{1 i}+\ldots+\beta_{k} x_{k i}\right)} .
$$

In this specification the contribution to the likelihood function of individual $i$ is similar to that of a binary latent class model,

$$
L_{i}=\pi\left\{\left[\frac{h_{1}\left(t \mid x_{i}\right)}{1-h_{1}\left(t \mid x_{i}\right)}\right]^{c_{i}} \prod_{j=1}^{t}\left[1-h_{1}\left(j \mid x_{i}\right)\right]\right\}+(1-\pi)\left\{\left[\frac{h_{2}\left(t \mid x_{i}\right)}{1-h_{2}\left(t \mid x_{i}\right)}\right]^{c_{i}} \prod_{j=1}^{t}\left[1-h_{2}\left(j \mid x_{i}\right)\right]\right\} .
$$




\subsection{The split-population model}

We will now account for the possibility that there are some unemployed individuals who may never find a job. Up to now we have neglected the existence of long-term survivors (or infinite durations). This approach has been used in the econometric literature in the context a split-population framework for a single risk (Schmidt and Witte, 1989) while Addison and Portugal (2003) offer a generalization of the split-population model to independent competing risks. ${ }^{3}$

To incorporate the possibility of "defective" risks we redefine the survival function (which represents the proportion of unemployed who not find a suitable job until $t)$ as $\tilde{S}(t)=(1-p)+p S(t)$ where $p$ is the proportion of unemployed who are indeed "susceptible" to the risk of failure. The survival probability is, therefore, given by the proportion of long-term survivors $(1-p)$ who do not exit into employment with probability 1, plus the proportion of "susceptible" individuals, $p$, multiplied by their corresponding probability of remaining unemployed until $t$, $S(t)$.

In order to guarantee that each $p$ lies between zero and one, the logit reparameterization for $p=\exp (\mu) /(1+\exp (\mu))$ was employed. This has no other consequence, in terms of finding evidence of long-term survivors, since it does not preclude $p$ from being as close to one (or zero) as needed. In this setup, the contribution of observation $i$ to the likelihood function is

$$
L_{i}=\left\{p \quad h\left(t \mid x_{i}\right) \prod_{j=1}^{t-1}\left[1-h\left(j \mid x_{i}\right)\right]\right\}^{c_{i}} \quad\left\{(1-p)+p \quad \prod_{j=1}^{t}\left[1-h\left(j \mid x_{i}\right)\right]\right\}^{1-c_{i}} .
$$

\section{Findings}

Results of fitting the proportional hazards model to the discrete duration data (the complementary log-log model) are presented in Table 1. From the first column of the table it can be seen that receipt of unemployment benefits depresses transitions into employment by no less than 52 percent compared with nonrecipients. The YOUNG variable appears to depress transition rates somewhat but only before

\footnotetext{
${ }^{3}$ These models are called "cure-rate" or long-term survival models in biostatistics.
} 
benefits are actually drawn. Once drawn, those in receipt of three months shorter benefits actually have 65 percent higher escape rates than their nearest neighbours.

(Table 1 near here)

Including jobless duration as a regressor (shown in the second column of the table) renders this effect of benefit duration largely unchanged while suggesting negative duration dependence in the data. Specifically, a 10 percent increase in elapsed duration at survey date is associated with a 2 percent reduction in escape rates over the following three months.

The introduction of six age dummies (recall that the reference category is the age "pair" 24 to 25 years of age), shown in the third column of the table, captures the pure effects of age on duration of joblessness. Familiarly, these age effects broadly indicate that escape rates decline strongly with age. ${ }^{4}$ The inclusion of the age dummies serves to reduce the effect of benefit receipt on joblessness and increase the coefficient for the interaction term (i.e. increase hazard rates for shorter maximum potential benefits). Neglecting to take age effects into account also apparently modestly understates the indication of negative duration dependence in the data.

In the final column of the table, we include controls for number of years of schooling, the unemployment rate, and dummies for marital status and physical handicap. It is clear that the other coefficient estimates are largely unaffected. The principal exception is the coefficient estimate for elapsed duration, which points to a further strengthening of negative duration dependence.

At this stage, then, we have obtained strong evidence of the effect of length of benefits on jobless duration by exploiting natural differences in the Portuguese benefits regime across nearly matched individuals in a framework that also identifies the pure effects of age on transitions. We have reported that benefit recipients having three months shorter potential maximum benefits have quarterly hazard

\footnotetext{
${ }^{4}$ The regression coefficient estimates were $-0.181,-0.647,-0.416,-0.415,-1.415$, and -1.080 , for the different age categories (29 and 30 years, 34 and 35 years, 39 and 40 years, 44 and 45 years, 49 and 50 years, and 54 and 55 years, respectively).
} 
rates that are 58 to 72 percent higher,cet.par. Moreover, the effects of simple benefit receipt are in line with other estimates for Portugal (e.g. Portugal and Addison, 2003).

(Table 2 near here)

But ceteris may not be paribus. In particular, despite the closeness of adjacent individuals, unobserved individual heterogeneity may still cast a shadow. Accordingly, in Table 2 we provide estimates for a two mass point hazard model. The heterogeneity we identify is that between more employable individuals (call them 'hares') and less employable individuals ("turtles"). Thus, for example, if we consider the results for the size of the mass points in the first column of the table it is apparent that the turtles have a base chance of finding work of 0.684 percent as compared with 20.36 percent for the hares. Note that these intercepts are computed as $1-\exp (-\exp (-4.982))$ and $1-\exp (-\exp (-1.480))$, respectively.

Continuing with the other results in the first column of Table 2 the effects of benefit receipt are substantial, leading to a 78.6 percent fall in the hazard relative to nonrecipients. These are much higher estimates than were reported in Table 1 and so, too, are the positive effects of shorter maximum benefit duration on escape rates into employment: three months fewer maximum benefits translate into a doubling of escape rates. The results in the second column of the table indicate that that adding in elapsed duration does not materially alter any of the results; for example, the findings for the slow movers (turtles) and fast movers (hares) are virtually unchanged at 0.729 percent and 20.7 percent, respectively. In this specification, the proportion of less-employable workers (turtles) is very large, corresponding to around 85 percent of the unemployed population.

From column (3), the introduction of the age dummies, controlling for the pure effect of age on joblessness, has four main effects. First, there is a major diminution in the effect of benefit receipt on jobless, which value is in line with the corresponding estimates in Table 1. Second, there is also a (more modest) reduction in the effects of shorter benefits once drawn on escape rates. These are 
approximately 72 percent, again much in line with the findings in Table 1 . Third the effect of elapsed duration is now both negative and statistically significant, which can be interpreted as indicating true duration dependence. Fourth, the young hares (the 24 and 25 year olds) have a base hazard rate of a little under 9 percent, while for turtles the escape rate is just 0.00018 percent. The proportion of less-employable workers (turtles) is now much smaller, corresponding to around 44 percent of the unemployed population. Adding in demographic controls and the unemployment rate in the fourth column of the table leaves the previous results largely unaltered, with the main change being a yet firmer indication of negative duration dependence.

\section{(Table 3 near here)}

As a final exercise, we exploit the suggestion of the two mass point hazard model (especially from the last two columns of Table 2) that the escape rates of an important subset of the sample - the turtles - are virtually zero. That is to say, in Table 3 we provide results for a more parsimonious split-population model that imposes the restriction that some escape rates are indeed zero or, equivalently, that some jobless durations are infinite (see Addison and Portugal, 2003). All the regression coefficient estimates thus now refer to the susceptible individuals. Focusing here on the results for the full specification contained in the last column of Table 3, we see that the base chance of transitioning into employment over a three-month period is a little over 10 percent for individuals in the reference category (25 year old nonrecipients, etc.) among those who will eventually find employment. These movers make up a little less than one-half of the population, meaning that for more than one-half of the population unemployment duration will be infinite. ${ }^{5}$ Not surprisingly the coefficient estimates identical to those displayed in Table 2. Receipt of benefits that are three months shorter in maximum duration than those of adjacent individuals results in higher escape rates into employment of 87 percent.

\footnotetext{
${ }^{5}$ The indication of a significant fraction of long-term unemployed - that is, of defective risks - is in line with the results presented in Addison and Portugal (2003).
} 


\section{Conclusions}

Typically, research points to much stronger disincentive effects for increases in maximum potential benefits than for changes in replacement rates. In Portugal, where replacement rates are virtually a datum, we report potent disincentive effects of longer benefit duration. Our identification strategy exploits the fact that maximum potential unemployment benefit duration is a deterministic function of age. We report that, among UI recipients, three months shorter potential maximum benefits translate into 53 to 106 percent higher escape rates into employment, after controlling for unobserved individual heterogeneity, These results reinforce the modern predisposition toward policy intervention that focuses more on duration of benefits than on replacement rates. 


\section{References}

Addison, J. And P. Portugal (2003). Unemployment Duration: Competing and Defective Risks. Journal of Human Resources, 38 (Winter), 156-191.

Atkinson, Anthony B. And John Micklewright (1991) Unemployment Compensation and Labor Market Transitions: A Critical Review. Journal of Econmomic Literature 29 (December): 1679-1727.

Carling, K., P-A Edin, A. Harkman, and Bertil Holmlund (1996) Unemployment Duration, Unemployment Benefits, and Labor Market Programs in Sweden. Journal of Public Economics 59 (March): 313-334.

Carling, K., Bertil Holmlund, And A. Vejsiu (2001) Do Benefit Cuts Boost Job Finding? Swedish Evidence from the 1990s. Economic Journal 111 (October): 766-790.

Card, David E., And Philip B. Levine (2000) Extended Benefits and the Duration of UI Spells: Evidence from the New Jersey Extended Benefits Program. Journal of Public Economics 78 (October): 107-138.

Katz, Lawrence F. And Bruce D. Meyer (1990) The Impact of the Potential Duration of Unemployment Benefits on the Duration of Unemployment. Journal of Public Economics 41 (February): 45-72.

Jenkins, Stephen (1995) Easy Estimation Methods for Discrete-Time Duration Models. Oxford Bulletin of Economics and Statistics 57 (February): 129-138.

Lalive, Rafael and Josef Zweimüller (2004) Benefit Entitlement and Benefit Duration - The Role of Policy Endogeneity. Journal of Public Economics 88 (December): 2587-2616.

Lalive, Rafael, Jan Van Ours, and Josef Zweimüller (2006) How Changes in Financial Incentives Affect the Duration of Unemployment. Review of Economic Studies 73 (October) :1009-1038. 
Meyer, Bruce D. (1990) Unemployment Insurance and Unemployment Spells. Econometrica 58 (July): 757-782.

Mortensen, Dale T. (1977) Unemployment Insurance and Job Search Decisions. Industrial and Labor Relations Review 30 (July): 505-517.

Portugal, Pedro and John T. Addison (2003) Six Ways to Leave Unemployment. IZA Discussion Paper 954 Bonn: Institute for the Study of Labor, December.

RøD, Knut and Tao Zhang (2003) Does Unemployment Compensation Affect Unemployment Duration? Economic Journal 113 (January): 190-206. Schmidt, P. And Witte, A.D. (1989) Predicting Criminal Recidivism Using Split Population Survival Models. Journal of Econometrics, 40 (January), 141-159.

Van Ours, Jan C. and Milan Vodopivec (2006) How Shortening the Potential Duration of Unemployment Benefits Affects the Duration of Unemployment: Evidence from a Natural Experiment. Journal of Labor Economics 24 (April): 351-378. 


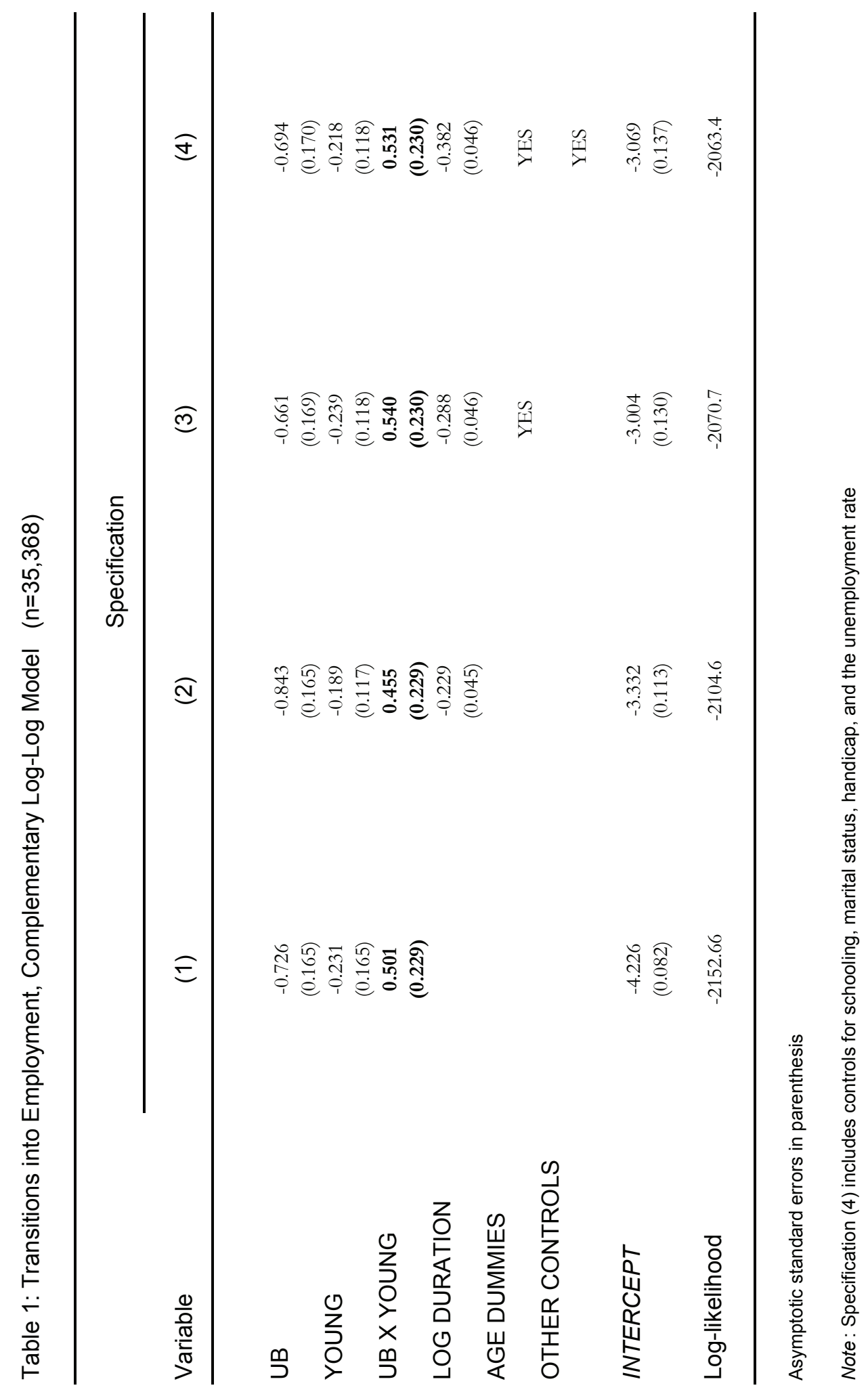




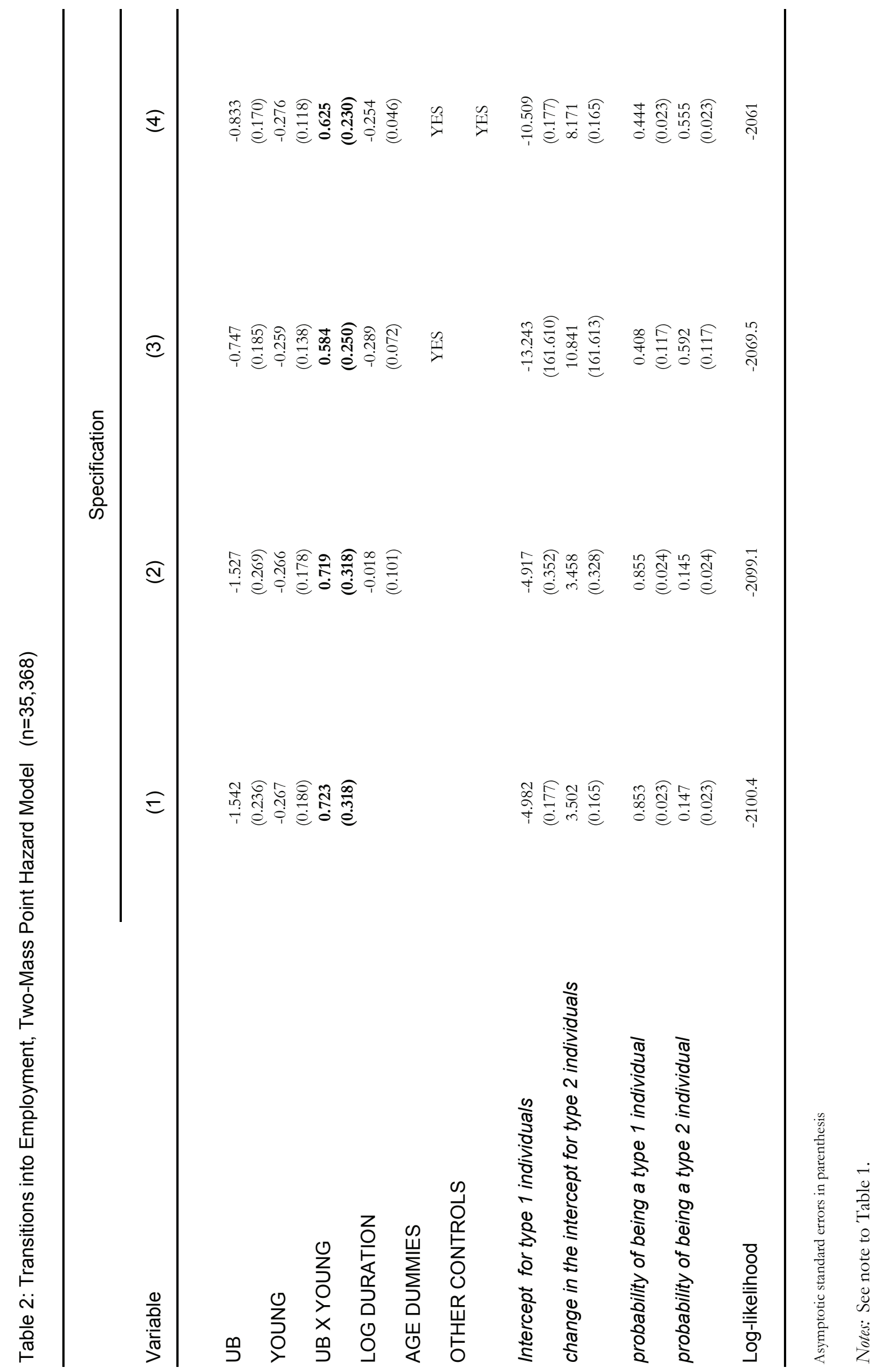




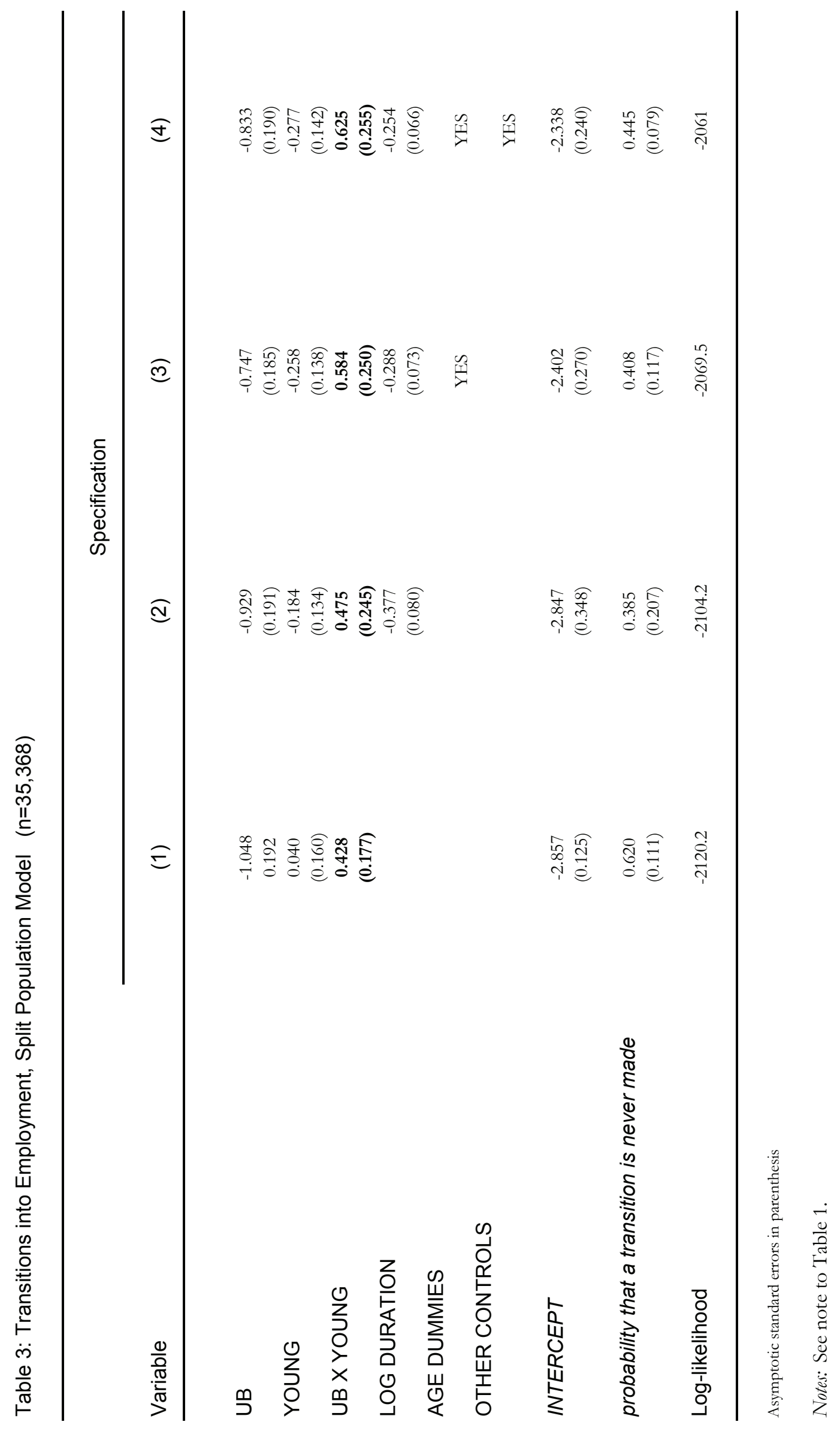

